\title{
REVIEW
}

\section{MicroRNAs in colorectal cancer stem cells: new regulators} of cancer stemness?

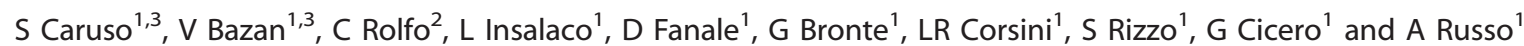

Recently, the hypothesis that colorectal tumors originate from a subpopulation of cells called 'cancer stem cells' (CSCs) or tumor-initiating cells, which exhibit stem-like features, has been confirmed experimentally in various human cancers. Several studies have confirmed the existence of colorectal CSCS (CRCSCs) and have demonstrated that this rare cell population can be isolated by the expression of specific cell surface biomarkers. MicroRNAs (miRNAs) are a class of small non-coding RNAs, which are crucial for post-transcriptional regulation of gene expression and participate in a wide variety of biological functions, including development, cell proliferation, differentiation, metabolism and signal transduction. Moreover, new evidences suggest that miRNAs could contribute to preserve stemness of embryonic stem cells and could be involved in maintaining stemness of CSCs. Recent studies have begun to outline the role of miRNAs in regulation of CRCSCs. This review aims to summarize the recent advancement about the roles of miRNAs in CRCSCs that may represent a step forward in understanding the molecular mechanisms and the possible approaches for colorectal cancer therapy.

Oncogenesis (2012) 1, e32; doi:10.1038/oncsis.2012.33; published online 12 November 2012

Subject Category: molecular oncology

Keywords: microRNAs; CSCs; CRC; stemness

\section{INTRODUCTION}

Colorectal cancer (CRC) is the third most common cancer worldwide that causes 655000 deaths per year. In 2011, CRC will account for $\sim 141000$ new cases and 49000 deaths in the United States, making it the second leading cause of death from cancer. ${ }^{1}$ Although early detection methods and therapeutic approaches have been studied to prolong patient survival in recent years, surgical resection is the most successful treatment. It is possible that microscopic neoplastic foci could remain after the surgical treatment and subsequently metastatic diseases could develop. ${ }^{2}$ CRC is a heterogeneous tumor and the existence of therapyresistant cancer cell populations can negatively affect adjuvant therapies, such as radiotherapy and chemotherapy. ${ }^{3}$

With regard to pathogenesis and molecular events, CRC is one of the best-characterized cancers. The accumulation of mutations involving oncogenes, tumor suppressor genes (gatekeepers) and repair/stability genes (caretakers) determines the development and progression from adenoma to cancer and metastatic disease. At the DNA level, these alterations are cumulative and include before adenomatous polyposis coli $(A P C)$ or $\beta$-catenin mutations and then mutation of other genes, such as K-Ras, p53 and transforming growth factor- $\beta$ (TGF- $\beta$ ), in the context of a growing genomic instability. ${ }^{3}$

In recent years, the cancer stem cell (CSC) model has been suggested to explain the functional heterogeneity and the carcinogenesis process of cancer (Figure 1). According to CSC hypothesis, a small fraction of cancer cells, which exhibit stem-like features, both self-renewal and pluripotency, have the ability of initiating and sustaining tumor growth, metastasis and resistance to therapy. ${ }^{4}$ CSCs, also called tumor-initiating cells, were first identified in hematologic malignancies and more recently in several solid tumors, such as CRC.,

MicroRNAs (miRNAs) are a recently discovered class of small non-coding RNA molecules. Mature miRNA can regulate gene expression by binding to $3^{\prime}$ untranslated regions of the complementary mRNA. This interaction triggers mRNA degradation or inhibition of protein synthesis. ${ }^{7}$ During the last decade, it has become clear that alterations in the expression of several miRNAs are extensively associated with the etiology and clinical outcome of many human cancers, including CRC, suggesting potential roles in carcinogenesis.

Recent findings suggest that miRNAs could be involved in maintaining stemness of colon CSCs, though the role of miRNAs in human colorectal CSCS (CRCSCs) remains poorly understood.

\section{CRC STEM CELLS}

Stem cells are unspecialized cells that are in general defined by two functional properties: the ability to self-renew for a long period of time and the potential to differentiate into other mature cells of the tissue of origin (multipotency). ${ }^{5,6,9}$

Intestinal stem cell population resides at the base of the colonic crypt and gives rise to the three major cell lineages, namely colonocytes, the primary absorptive cell; goblet cells, the mucinsecreting cell; enteroendocrine cells, the hormone-producing population endocrine. ${ }^{9}$

'Section of Medical Oncology, Department of Surgical and Oncology Sciences, University of Palermo, Palermo, Italy and ${ }^{2}$ Oncology Department, University Hospital of Antwerp, Edegem, Antwerp, Belgium. Correspondence: Professor A Russo, Section of Medical Oncology, Department of Surgery and Oncology Sciences, University of Palermo, Via del Vespro 129, 90127 Palermo, Italy.

E-mail: antonio.russo@usa.net

${ }^{3}$ These authors contributed equally to this work.

Received 6 August 2012; revised 24 September 2012; accepted 29 September 2012 


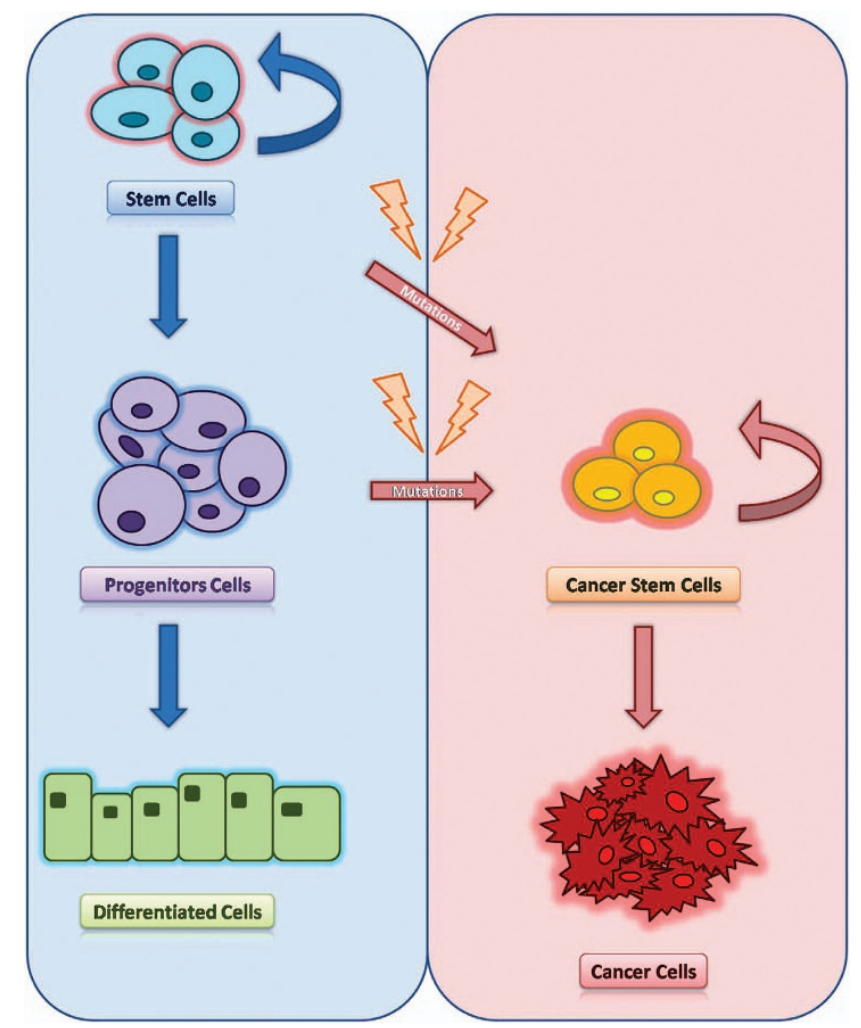

Figure 1. Cancer stem cell model. The development of various tissues is supported by stem cells. These cells, in the physiological context, proliferate, become progenitor cells, and finally acquire a differentiated phenotype. In the course of life, at the level of stem cells can accumulate oncogenic mutations and genetic aberration that give rise to CSCs. CSCs are defined by characteristics similar to those of normal stem cells, mainly their abilities to self-renew, a characteristic that leads to tumor development.

The concept that tumors contain heterogeneous cell populations with diverse biological characteristics and potentials has long been recognized. The traditional model of tumorigenesis suggests that this heterogeneity can be explained by genetic aberrations and microenvironmental influence, making each tumor cell capable of initiation and propagation. ${ }^{10}$

Recently, the 'cancer stem cell' theory of carcinogenesis has proposed that within the tumor mass there is a predetermined cell population with a 'stem cell' phenotype, able to perpetuate the cancer, whereas the rest of the neoplastic cells are unable of self-renewal. ${ }^{6}$ This suggests that tumors may arise and grow due to CSC formation, which could be an endless reserve to tumor progression and subsistence (Figure 1).

Although increasing evidence supports the existence of the CSCs, the source of these cells remains unclear. In fact, it has not been recognized unequivocally that CSCs originate from normal stem cells, but also genetic or epigenetic changes may confer stem-like ability on a progenitor or differentiated cell. ${ }^{11}$ In this context, miRNAs may have a key role. Evidence that miRNAs are involved in stem cell fate is provided by the fact that the absence of DGCR8, an RNA-binding protein essential for miRNA biogenesis, in knockout embryonic stem cells is responsible for slow proliferation rates and defective differentiation. ${ }^{12}$

It has long been accepted the existence of CRCSCs in human $\mathrm{CRC}^{13-15}$ and the potential role of CRCSCs to tumor progression, metastasis and therapeutic failure.

According to the CSC model, it has been proposed that the first mutation occurs in a colonic stem cell located at the crypt bottom that in the course of his long life can accumulate oncogenic mutations (Figure 1). Although the concept that CRC develops as a result of a sequence of mutations occurring during the clonal expansion of a single stem cell has been widely accepted, the existence of CRCSCs had not been experimentally demonstrated until recently due to difficulties in identifying a specific biomarker for this rare cell population. In the past few years, new evidences have supported the existence of CRCSCs, confirming that the neoplastic cell population of CRC can be isolated by the expression of specific cell surface biomarkers. ${ }^{3}$

Recently, experiments using a combination of flow cytometry to identify a 'putative' stem cell population and xenograft models involving immunodeficient mice to determine their tumorinitiating potential have assessed the expression of specific CRCSC biomarkers. ${ }^{16}$

In the first two studies, CD133, also known as Prominin-1, was used to identify the tumorigenic cell population within CRC. ${ }^{13,15}$

$\mathrm{O}^{\prime}$ Brien et al. ${ }^{13}$ isolated $\mathrm{CD} 133^{+}$cells from both primary and metastatic human CRCs and injected the sorted cells in the renal capsule of nonobese diabetic/severe combined immunodeficiency (NOD/SCID) mice. CD $133^{+}$cells readily developed tumors in mice, whereas the $\mathrm{CD}_{133^{-}}$cell population was unable to generate tumors even after serial transplantation in mice. Moreover, tumor xenografts generated by $\mathrm{CD} 133^{+}$cells displayed the same tumor phenotype of the parental tumor and were reproducibly maintained upon serial transplantation.

Similary, in the second study, Ricci-Vitiani et al. showed that $\mathrm{CD} 133^{+}$cells, accounting for $\sim 2.5 \%$ of tumor cells, could be maintained in vitro as colon 'tumor spheres' for $>1$ year, without losing their in vivo tumorigenic potential. ${ }^{15}$

Both studies demonstrated the expression of CD133 also in normal colon tissue, although at lower frequency, reinforcing the hypothesis that $\mathrm{CD}_{133^{+}}$cells in cancer samples might result from oncogenic transformation of normal colonic stem cells.

Subsequently, the cell adhesion molecule CD44 and the epithelial surface antigen (EpCAM) were proposed as alternative markers for CRCSC isolation, with further enrichment by CD166. Subcutaneous injection of purified $\mathrm{CD}_{4}{ }^{+} / \mathrm{EpCAM}_{\text {high }}$ cells into $\mathrm{NOD} / \mathrm{SCID}$ mice resulted in high-frequency generation of tumor xenograft, whereas $\mathrm{CD}_{4}{ }^{-} / \mathrm{EpCAM}_{\text {low }}$ cells did not have this ability. Moreover, when $\mathrm{CD} 44^{+} / \mathrm{EpCAM}_{\text {high }}$ are used together with the mesenchymal stem cell marker CD166 was possible to observe an increase in the success of tumor xenograft. ${ }^{14}$

In a more recent study, the detoxifying enzyme aldehyde dehydrogenase 1 (ALDH1) has been proposed as a promising new marker for normal and malignant human colonic stem cells. As few as $25 \mathrm{ALDH}^{+}{ }^{+}$cancer cells, isolated by flow cytometry, were able to generate tumor xenografts in NOD/SCID mice. Notably, a subsequent isolation of cancer cells using a second marker (CD44 or CD133 serially) increased modestly tumorinitiating ability, implying that ALDH1 can be used as another putative CRCSC marker ${ }^{17}$

In addition to CD133, CD166, CD44, EpCAM and ALDH1, a potential CRCSC marker, is proposed to be the somatic intestinal stem/progenitor cell marker Lgr5 (leucine-rich repeat-containing G-protein-coupled receptor 5). The Lgr5 expression is variable among CRC cases, correlated significantly with lymphatic and vascular invasion, lymph node metastasis and tumor stage, suggesting the involvement of this marker in tumor progression. ${ }^{18}$

The isolation of CRCSC is a very important step to understand the molecular pathways activated or expressed only in CSC or to discover the molecular mechanisms underlying the regulation of these cells, as miRNAs.

\section{SIGNALING PATHWAYS IN CRC AND CSCs}

The homeostatic self-renewal of the intestine depends on a complex network of evolutionary highly conserved signaling pathways that control many cellular processes, including proliferation, differentiation, migration and cell death. 
In CRC, the alteration of these signaling pathways, such as Wnt/ $\beta$-catenin, Notch, TGF- $\beta$, bone morphogenetic proteins (BMPs) and Hedgehog $(\mathrm{SHH})$, is closely related to disrupted stem cell selfrenewal and differentiation.

It has long been accepted that the canonical Wnt pathway is an important regulator of normal intestinal stem cells and more recently has been proposed a role in CRCSCs regulation. ${ }^{19,20}$ The role of Wnt pathway in CRC has been highlighted by the discovery of mutations in the APC gene as the cause of familial adenomatous polyposis, which is a hereditary cancer predisposition syndrome. ${ }^{21}$ Experiments on knockout mice have shown that Wnt signaling is involved in endoderm formation and also exerts fundamental role in crypt development, maintenance and proliferation. ${ }^{22}$ Moreover, Wnt signaling is involved in the process of epithelial to mesenchymal transition. ${ }^{10}$

Notch is another important pathway involved in the regulation of intestinal stem cells and the activation of Notch signaling inhibits differentiation and stimulates progenitor proliferation. ${ }^{23}$ A recent study on CRC cell lines suggested that Notch knockdown reduced proliferation, increased apoptosis and decreased clonogenicity, whereas overexpression of Notch had the opposite effect. ${ }^{24}$ In addiction, inhibition of Notch signaling in $\mathrm{APC} /$ multiple intestinal neoplasia $\left(\mathrm{APC}^{\mathrm{min}}\right)$ mice reduce cancer proliferation, inhibit CSC self-renewal and increase differention to goblet cells. ${ }^{25}$ Furthermore, Notch pathway is able to interact with Wnt signaling through a not entirely clear mechanism. ${ }^{26}$ The interaction between the Notch and Wnt signaling pathways and the role of Notch in the inhibition of differentiation suggest that Notch could be involved in the regulation of CSCs.

The TGF- $\beta$ signaling pathway has an important role in intestinal stem cell function and carcinogenesis because it is involved in the regulation of several biologic processes, such as cell proliferation, differentiation, migration and apoptosis, and for these reasons it is one of the most commonly altered pathways in human cancers. $^{27,28}$ Recently, it has been suggested that TGF- $\beta$ signaling is involved in gut endoderm development and the transition of stem cells to a more differentiated phenotype. ${ }^{29}$ Several authors also suggest that the TGF- $\beta$ and Wnt pathways synergistically promote CRC tumorigenesis, confirming that disruption of both signaling pathways cooperate to drive tumor initiation, likely in colonic stem cells. ${ }^{30-33}$

BMPs are a subgroup of TGF- $\beta$ superfamily members that are involved in controlling intestinal differentiation. In particular, it has been reported that BMP4 promotes terminal differentiation, apoptosis and chemosensitization of CRCSCs, highlighting the potential role of disrupted BMP4 signaling in CRC. ${ }^{34}$ Finally, the role of Hedgehog in CRC remains controversial but appears to be essential for human colon cancer growth, recurrence, metastases and stem cell expansion, ${ }^{35}$ probably acting by Wnt suppressor. ${ }^{36}$

\section{MICRORNAs IN CRCSCs}

miRNAs are a class of endogenous, small (18-25 nucleotide in length), single-stranded non-coding RNAs that regulate gene expression at post-trascriptional level by acting on specific messenger targets, inducing mRNA degradation or translational arrest. In short, miRNAs biogenesis begins with primary miRNAs, inactive forms that are transcribed by RNA polymerase II or excised as introns portions. ${ }^{37-39}$ The primary miRNAs are processed in the nucleus by the ribonuclease Drosha and the resultant precursor miRNA (pre-miR) is then exported to the cytoplasm where the ribonuclease Dicer processes it again to form the active miRNA. miRNA is now transferred to the Argonauta protein that is located within the RNA-induced silencing complex (RISC). The miRNA RISC can now interact with the complementary mRNA to repress their translation. ${ }^{37-39}$ Interestingly, a single miRNA can regulate many mRNAs and a single mRNA can be the target of several miRNAs. MiRNAs are involved in several biological functions, including development, cell proliferation, differentiation, metabolism and signal transduction. Recent studies have shown that abnormal patterns of miRNAs are present in human cancers, suggesting potential role in carcinogenesis. ${ }^{7,8,40}$

In 2003, Michael et $a .^{41}$ reported for the first time the miRNAs alteration in CRC, showing the downregulation of miR-143 and miR-145 in CRC tumor tissues compared with normal tissues. Over the years, several studies have shown miRNAs that are extensively

Table 1. microRNAs involved in colorectal cancer

\begin{tabular}{|c|c|}
\hline Downregulated & Upregulated \\
\hline let-7 & let-7g \\
\hline let-7a-1 & $\overline{\text { miR-10a }}$ \\
\hline let-7b & miR-15b \\
\hline let-7g & $\underline{\text { miR-16 }}$ \\
\hline$\overline{\mathrm{miR}-1}$ & $\overline{\mathrm{miR}-17}$ \\
\hline miR-9-3 & miR-17-5p \\
\hline miR-10b & miR-18a \\
\hline miR-16 & miR-19a \\
\hline$\overline{\mathrm{miR}-23 \mathrm{~b}}$ & miR-19b \\
\hline miR-24 & miR-20 \\
\hline miR-26a & miR-20a \\
\hline miR-30a-3p & miR-21 \\
\hline miR-30a-5p & $\operatorname{miR}-21^{*}$ \\
\hline miR-30c & miR-23a \\
\hline$\overline{\mathrm{miR}-101}$ & miR-25 \\
\hline miR-102 & miR-27a \\
\hline miR-125a & miR-27b \\
\hline$\overline{\text { miR-132 }}$ & miR-29a \\
\hline$\overline{\mathrm{miR}-133 a}$ & miR-29b \\
\hline miR-133b & miR-30c \\
\hline miR-138 & $\overline{\mathrm{miR}-30 \mathrm{e}}$ \\
\hline miR-139 & miR-31 \\
\hline miR-143 & miR-34a \\
\hline miR-145 & miR-92 \\
\hline miR-181a & miR-92a \\
\hline miR-181b & miR-93 \\
\hline$\overline{\mathrm{miR}-192}$ & miR-93-1 \\
\hline miR-195 & miR-95 \\
\hline$\overline{\mathrm{miR}-200 \mathrm{~b}}$ & miR-96 \\
\hline miR-210 & miR-106a \\
\hline miR-215 & miR-106b, \\
\hline miR-218 & miR-107 \\
\hline miR-224 & miR-124b \\
\hline$\overline{\text { miR-296 }}$ & miR-125a \\
\hline miR-320 & $\overline{m i R-130 b}$ \\
\hline miR-372 & miR-132 \\
\hline miR-378* & $\overline{\operatorname{miR}-133 a}$ \\
\hline miR-455 & $\overline{m i R-135 b}$ \\
\hline miR-484 & miR-141 \\
\hline miR-422a, & miR-147 \\
\hline miR-422b & miR-151 \\
\hline miR-497 & miR-152 \\
\hline & miR-181b \\
\hline & $\overline{\text { miR-182 }}$ \\
\hline & miR-183 \\
\hline & miR-185 \\
\hline & miR-191 \\
\hline & miR-195 \\
\hline & $\overline{\mathrm{miR}-199 a}$ \\
\hline & miR-200c \\
\hline & miR-203 \\
\hline & miR-221 \\
\hline & miR-224 \\
\hline & $\overline{\mathrm{miR}-339}$ \\
\hline & miR-510 \\
\hline & miR-513 \\
\hline
\end{tabular}

miRNAs with conflicting expression levels in the two groups are underlined and in bold. 
deregulated in CRC, as summarized in Table $1 .^{41-49}$ Moreover, other studies have reported that there are different miRNA profiles in each tumor subtype, depending on tumor location and mutation status of $p 53$ and $K$-Ras. ${ }^{49}$

To date, numerous studies have described the role of miRNAs in normal stem cells of many tissues, whereas only few studies are available on the function of miRNAs in CSCs. Recently, several authors have begun to outline the role of miRNAs in regulation of CRCSCs. The first evidence showed that miR-17-92 cluster and its target, E2F1, exhibit a similar expression pattern in developing embryonic tissue and adult CRC. Furthermore, inhibition of miR17-5p, a member of the miR-17-92 cluster, decreased DLD1 cancer cell proliferation and clonogenicity. In situ hybridization showed highest expression of miR-17-5p in the crypt progenitor compartment, which suggests that it is a factor involved in stem cells regulation. ${ }^{50}$ Song et al. $^{51,52}$ in two different studies emphasized the miR-140 and miR-215 involvement in CRCSCs. They showed that the overexpression of miR-140 and mir-215 can inhibit CRC cell proliferation and cause cell cycle arrest. CRC stem-like cells,

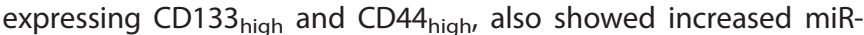
140 and miR-215 expression levels by four- and three-fold, respectively, compared with control parental CRC cells. In 2010, Zhang et al. ${ }^{53}$ reported a different miRNAs expression profile in human colonic adenocarcinoma cell line HT-29 selected by CD133 positivity and high expression of stemness genes, such as Wnt, BMI1, Notch1 and OCT3/4. Moreover, these cells were able to form tumor spheres in vitro and tumors in BALB/c nude female mice. The authors identified, through microarray analysis, 19 differentially expressed miRNAs in $\mathrm{CD}_{13}{ }^{+}$CRCSCs compared with $C D 133^{-}$population, 11 miRNAs were found upregulated, including miR-16-2*, miR-105, miR-155, miR-181b, miR-185, miR423-5p, miR-455-3p, miR-455-5p, miR-494, miR-744, miR-1826 and 8 miRNAs were downregulated, including miR-31, miR-151-3p, miR-151-5p, miR-221, miR-320d, miR-429, miR-548d-5p and miR-636. ${ }^{53}$ Some of these, such as miR-429 and miR-155 are involved in CSC differentiation and epithelial-mesenchymal transition. $^{54,55}$ Birtarte et al. ${ }^{56}$ performed miRNA profiling in colonspheres with properties of CSCs obtained from different colon cancer cell lines and showed that miR-451 was abundantly downregulated. Ectopic expression of miR-451 caused a decrease in self-renewal, tumorigenicity and chemoresistance to irinotecan in colonspheres. They identified cyclooxygenase-2 as an indirect miR-451 target gene involved in CSC growth. MiR-451 targets macrophage migration inhibitory factor (MIF) gene, involved in the expression of cyclooxygenase- 2 that allows Wnt activation, which is essential for CSC growth. ${ }^{56}$ Another study reported that HCT-116 and HT-29, CSCs-enriched cell lines, show from three- to seven- fold overexpression of miR-21. MiR-21 upregulation induces an increase of $\beta$-catenin levels, TCF/LEF activity and the expression of c-Myc, cyclin-D, which are also increased in CSCs and causes a decrease of TGF $\beta$ R2, which is involved in differentiation. For this reason, the authors reported that miR-21 can have an important role in regulating stemness by modulating TGF $\beta R 2$ signaling in CRC cells. ${ }^{57}$ Additional miRNA profiling in colon CSC lines, SW1116csc, has resulted in 46 differentially expressed miRNAs. The miR-93 expression level was the lowest in SW1116csC compared with differentiated colon cancer cells. Overexpression of miR-93 consistently inhibited cell proliferation and colony formation of colon CSCs by targeting histone deacetylase 8 and the transducin-like enhancer of Split (TLE4), which inhibit Wnt/ $\beta$ catenin signaling pathway. ${ }^{58}$

Recently, Zhu et $a l^{59}$ demonstrated that Achaete scute-like 2 (Ascl2) is involved in maintenance of cancer progenitor cells. Ascl2 blockade in HT-29 cells significantly reduced the expression levels of stemness-associated genes, such as CD133, Lgr5, Oct4, Bmi1, Sox2 and C-myc and led to significant inhibition of tumorsphere formation compared with control. Furthermore, the authors identified 84 differentially expressed miRNAs in shRNA-Ascl2/HT29 cells compared with shRNA-control/HT-29 cells, using microarray analysis. Among these, miRNA-17, miRNA-20a and miRNA-302b were significantly downregulated, whereas, let-7b, miRNA-124, miRNA-125b were significantly upregulated but only miR-302b mimic restored the tumor spheres formation and the self-renewal of shRNA-Ascl2/HT-29, increasing Ascl2 mRNA and protein levels. ${ }^{59}$ In 2012, Xu et al. $^{60}$ reported that the side population cells sorted from CRC possess CSC-like properties, such as self-renewal, differentiation, resistance to chemotherapy, invasive and strong tumor formation ability. Microarray analysis shows that miR-328 was significantly downregulated in side population cells and for this reason can represent a potential stemness miRNA with an important role in maintaining cancer stem-like phenotype. Table 2 summarizes all the miRNAs that have been found deregulated in CRCSCs.

Analysis of several online databases (Tarbase, miRBase, mirò) indicates that these miRNAs not directly interact with mRNAs of human stemness genes, such as Wnt/ $\beta$-catenin, NOTCH1, TGF- $\beta$ and Hedgehog. However, the studies reported above suggest that miRNAs involved in CRCSCs may interact with signaling pathways, mediated by these genes, that regulate the stem cells.

\section{THERAPEUTIC IMPLICATIONS}

Recent evidence suggests that miRNAs may represent potential new therapeutic approaches in cancer treatment. Moreover,

Table 2. Summary of potential deregulated miRNAs in CRCSCs

Downregulated

miR-31, miR-151-3p, miR-151-5p, miR-221, miR-320d, miR-429, miR-548d-5p, miR-636 miR-451

miR-93, miR-1231, miRPlus-F1080, miR-524-3p, miR-886-3p, miR-561, miR-497, miR-23a, miR-886-5p, miRPlus-A1087, miRPlus-E1170
Upregulated

miR-17-5p

$\operatorname{miR}-140$

miR-215

miR-16-2*, miR-105, miR-155, miR-181b, miR-185, miR-423-5p, miR-455-3p, miR-455-5p, miR-494, miR-744, miR-1826

miR-21

miRPlus-E1 102, miR-138-2, miR-31, miR-17, miR-374a, miR-424, miRPlus-F1181, miRPlus-E1238, miR-542-3p, miR-582-3p, miR-584, miR-522, miR-590-5p, miR-487b, miR-29c, miR-96, miR-193a-3p, miR-20a, miR-301a, miRPlus-E1106, miR-30e, miR-874, miR-19a miR-519a, miRPlus-A1065, miR-521, miR-876-5p, miR-493, miR101, miR-32, miR-33a, miR-194, miR-215, miR-29b, miR-192 miR-302b
Studies

Monzo et al. ${ }^{50}$ Song et al. ${ }^{51}$ Song et al. ${ }^{52}$ Zhang et al. ${ }^{53}$

Bitarte et al. ${ }^{56}$ Yu et al. ${ }^{57}$ Yu et $a .^{58}$ 
CSC research and the increasing evidences that many cancer types, such as CRC, have their origin in CSC population provide novel approaches that could be used specifically for cancers with resistance to current therapies. ${ }^{61}$ Despite this, today we know very little about therapeutic implications of miRNAs in CRCSCs. To date, only two studies have shown that miRNAs contribute to CRCSC therapeutic resistance by modulating CRCSC-specific signaling pathways. In 2009, Song et al. ${ }^{51}$ reported that miR-140 confer a methotrexate and 5-fluoroucil-resistant phenotype in CD133 high $C D 44_{\text {high }}^{+}$colon cancer cells by inhibiting cell proliferation by targeting histone deacetylase 4 . In 2010, the same authors showed that miRNA-215 enhances the chemoresistance of CD133 $3_{\text {high }}^{+}$CD44 high colon cancer cells to methotrexate and Tomudex by inhibiting cell proliferation and inducing G2-arrest through the suppression of DTL expression. ${ }^{52}$ Taken together, these studies suggest that some miRNAs may have a key role in the mechanism of tumor chemoresistence.

\section{CONCLUSIONS}

In summary, increasing evidence suggests that CSCs or tumorinitiating cells cause tumor establishment, progression, metastasis and therapeutic failure. However, the role of miRNAs in human CRCSCs remains poorly understood. Recently, several research groups have begun to outline the role of miRNAs in the maintenance of stemness of CRCSCs. These studies suggest that some miRNAs can have a key role in the regulation of CRCSCs by interacting, directly or indirectly, on signaling pathways implicated in cancer stemness. Nevertheless to date, there is little information about the differences that exist between normal colorectal stem cell and CRCSCs, concerning miRNAs expression.

The identification of miRNAs involved in CRCSCs may represent a step forward in understanding the molecular mechanisms and characterization of CRCSCs and simultaneously may be useful to develop therapeutic approaches that specifically target this rare population of cells.

\section{CONFLICT OF INTEREST}

The authors declare no conflict of interest.

\section{REFERENCES}

1 Zhai $\mathrm{H}$, Ju J. Implications of microRNAs in colorectal cancer development, diagnosis, prognosis, and therapeutics. Front Genet 2011; 2: 78.

2 Zlobec I, Lugli A. Prognostic and predictive factors in colorectal cancer. J Clin Pathol 2008; 61: 561-569.

3 Wilson BJ, Schatton T, Frank MH, Frank NY. Colorectal cancer stem cells: biology and therapeutic implications. Curr Colorectal Cancer Rep 2011; 7: $128-135$.

4 Kemper K, Rodermond H, Colak S, Grandela C, Medema JP. Targeting colorectal cancer stem cells with inducible caspase-9. Apoptosis 2012; 17: 528-537.

5 Boman BM, Wicha MS. Cancer stem cells: a step toward the cure. J Clin Oncol 2008; 26: 2795-2799.

6 Abdul Khalek FJ, Gallicano Gl, Mishra L. Colon cancer stem cells. Gastrointest Cancer Res 2010; Suppl 1: S16-S23.

7 Bartel DP. MicroRNAs: genomics, biogenesis, mechanism, and function. Cell 2004; 116: $281-297$

8 Zhang B, Pan X, Cobb GP, Anderson TA. MicroRNAs as oncogenes and tumor suppressors. Dev Biol 2007; 302: 1-12.

9 Ricci-Vitiani L, Fabrizi E, Palio E, De Maria R. Colon cancer stem cells. J Mol Med 2009; 87: 1097-1104.

10 Vries RG, Huch M, Clevers H. Stem cells and cancer of the stomach and intestine. Mol Oncol 2010; 4: 373-384.

11 Huntly BJ, Gilliland DG. Leukaemia stem cells and the evolution of cancerstem-cell research. Nat Rev Cancer 2005; 5: 311-321.

12 Wang Y, Medvid R, Melton C, Jaenisch R, Blelloch R. DGCR8 is essential for microRNA biogenesis and silencing of embryonic stem cell self-renewal. Nat Genet 2007; 39: 380-385.
13 O'Brien CA, Pollett A, Gallinger S, Dick JE. A human colon cancer cell capable of initiating tumour growth in immunodeficient mice. Nature 2007; 445: 106-110.

14 Dalerba P, Dylla SJ, Park IK, Liu R, Wang X, Cho RW et al. Phenotypic characterization of human colorectal cancer stem cells. Proc Natl Acad Sci USA 2007; 104: 10158-10163.

15 Ricci-Vitiani L, Lombardi DG, Pilozzi E, Biffoni M, Todaro M, Peschle C et al. Identification and expansion of human colon-cancer-initiating cells. Nature 2007; 445: $111-115$

16 Vermeulen L, Todaro $M$, de Sousa Mello F, Sprick MR, Kemper K, Perez Alea $\mathrm{M}$ et al. Single-cell cloning of colon cancer stem cells reveals a multilineage differentiation capacity. Proc Natl Acad Sci USA 2008; 105: 13427-13432.

17 Huang EH, Hynes MJ, Zhang T, Ginestier C, Dontu G, Appelman H et al. Aldehyde dehydrogenase 1 is a marker for normal and malignant human colonic stem cells (SC) and tracks SC overpopulation during colon tumorigenesis. Cancer Res 2009; 69: 3382-3389.

18 Uchida H, Yamazaki K, Fukuma M, Yamada T, Hayashida T, Hasegawa $\mathrm{H}$ et al. Overexpression of leucine-rich repeat-containing $\mathrm{G}$ protein-coupled receptor 5 in colorectal cancer. Cancer Sci 2010; 101: 1731-1737.

19 Espada J, Calvo MB, Diaz-Prado S, Medina V. Wnt signalling and cancer stem cells. Clin Transl Oncol 2009; 11: 411-427.

20 de Sousa EM, Vermeulen L, Richel D, Medema JP. Targeting Wnt signaling in colon cancer stem cells. Clin Cancer Res 2011; 17: 647-653.

21 Haegebarth A, Clevers $\mathrm{H}$. Wht signaling, lgr5, and stem cells in the intestine and skin. Am J Pathol 2009; 174: 715-721.

22 Fevr T, Robine S, Louvard D, Huelsken J. Wnt/beta-catenin is essential for intestinal homeostasis and maintenance of intestinal stem cells. Mol Cell Biol 2007; 27: 7551-7559.

23 Fre $S$, Huyghe $M$, Mourikis $P$, Robine S, Louvard D, Artavanis-Tsakonas S. Notch signals control the fate of immature progenitor cells in the intestine. Nature 2005; 435: 964-968.

24 Zhang Y, Li B, Ji ZZ, Zheng PS. Notch1 regulates the growth of human colon cancers. Cancer 2010; 116: 5207-5218.

25 van Es JH, van Gijn ME, Riccio O, van den Born M, Vooijs M, Begthel H et al. Notch/ gamma-secretase inhibition turns proliferative cells in intestinal crypts and adenomas into goblet cells. Nature 2005; 435: 959-963.

26 Anderson EC, Wong MH. Caught in the Akt: regulation of Wnt signaling in the intestine. Gastroenterology 2010; 139: 718-722.

27 Massague J, Blain SW, Lo RS. TGFbeta signaling in growth control, cancer, and heritable disorders. Cell 2000; 103: 295-309.

28 Boman BM, Huang E. Human colon cancer stem cells: a new paradigm in gastrointestinal oncology. J Clin Oncol 2008; 26: 2828-2838.

29 Mishra L, Derynck R, Mishra B. Transforming growth factor-beta signaling in stem cells and cancer. Science 2005; 310: 68-71.

30 Barnard JA, Beauchamp RD, Coffey RJ, Moses HL. Regulation of intestinal epithelial cell growth by transforming growth factor type beta. Proc Natl Acad Sci USA 1989; 86: $1578-1582$.

31 Alberici P, Jagmohan-Changur S, De Pater E, Van Der Valk M, Smits R, Hohenstein $\mathrm{P}$ et al. Smad4 haploinsufficiency in mouse models for intestinal cancer. Oncogene 2006; 25: 1841-1851.

32 Takaku K, Oshima M, Miyoshi H, Matsui M, Seldin MF, Taketo MM. Intestinal tumorigenesis in compound mutant mice of both Dpc4 (Smad4) and Apc genes. Cell 1998; 92: 645-656.

33 Munoz NM, Upton M, Rojas A, Washington MK, Lin L, Chytil A et al. Transforming growth factor beta receptor type II inactivation induces the malignant transformation of intestinal neoplasms initiated by Apc mutation. Cancer Res 2006; 66: 9837-9844.

34 Lombardo Y, Scopelliti A, Cammareri P, Todaro M, lovino F, Ricci-Vitiani L et al. Bone morphogenetic protein 4 induces differentiation of colorectal cancer stem cells and increases their response to chemotherapy in mice. Gastroenterology 2011; 140: 297-309.

35 Gulino A, Ferretti E, De Smaele E. Hedgehog signalling in colon cancer and stem cells. EMBO Mol Med 2009; 1: 300-302.

36 Medema JP, Vermeulen L. Microenvironmental regulation of stem cells in intestinal homeostasis and cancer. Nature 2011; 474: 318-326.

37 Filipowicz W, Bhattacharyya SN, Sonenberg N. Mechanisms of post-transcriptional regulation by microRNAs: are the answers in sight? Nat Rev Genet 2008; 9: 102-114.

38 Papagiannakopoulos T, Kosik KS. MicroRNAs: regulators of oncogenesis and stemness. BMC Med 2008; 6: 15.

39 Wijnhoven BP, Michael MZ, Watson DI. MicroRNAs and cancer. Br J Surg 2007; 94 : 23-30.

40 He L, Hannon GJ. MicroRNAs: small RNAs with a big role in gene regulation. Nat Rev Genet 2004; 5: 522-531.

41 Michael MZ, O' Connor SM, van Holst Pellekaan NG, Young GP, James RJ. Reduced accumulation of specific microRNAs in colorectal neoplasia. Mol Cancer Res 2003; 1: 882-891. 
42 Volinia S, Calin GA, Liu CG, Ambs S, Cimmino A, Petrocca F et al. A microRNA expression signature of human solid tumors defines cancer gene targets. Proc Natl Acad Sci USA 2006; 103: 2257-2261.

43 Bandres E, Cubedo E, Agirre X, Malumbres R, Zarate R, Ramirez N et al. Identification by real-time PCR of 13 mature microRNAs differentially expressed in colorectal cancer and non-tumoral tissues. Mol Cancer 2006; 5: 29.

44 Rossi L, Bonmassar E, Faraoni I. Modification of miR gene expression pattern in human colon cancer cells following exposure to 5 -fluorouracil in vitro. Pharmacol Res 2007; 56: 248-253.

45 Nakajima G, Hayashi K, Xi Y, Kudo K, Uchida K, Takasaki K et al. Non-coding MicroRNAs hsa-let-7g and hsa-miR-181b are associated with chemoresponse to S-1 in colon cancer. Cancer Genomics Proteomics 2006; 3: 317-324.

46 Schepeler T, Reinert JT, Ostenfeld MS, Christensen LL, Silahtaroglu AN, Dyrskjot L et al. Diagnostic and prognostic microRNAs in stage II colon cancer. Cancer Res 2008; 68: 6416-6424.

47 Schetter AJ, Leung SY, Sohn JJ, Zanetti KA, Bowman ED, Yanaihara N et al. MicroRNA expression profiles associated with prognosis and therapeutic outcome in colon adenocarcinoma. JAMA 2008; 299: 425-436.

48 Arndt GM, Dossey L, Cullen LM, Lai A, Druker R, Eisbacher M et al. Characterization of global microRNA expression reveals oncogenic potential of miR-145 in metastatic colorectal cancer. BMC Cancer 2009; 9: 374.

49 Slattery ML, Wolff E, Hoffman MD, Pellatt DF, Milash B, Wolff RK. MicroRNAs and colon and rectal cancer: differential expression by tumor location and subtype. Genes Chromosomes Cancer 2011; 50: 196-206.

50 Monzo M, Navarro A, Bandres E, Artells R, Moreno I, Gel B et al. Overlapping expression of microRNAs in human embryonic colon and colorectal cancer. Cell Res 2008; 18: 823-833.

51 Song B, Wang Y, Xi Y, Kudo K, Bruheim S, Botchkina Gl et al. Mechanism of chemoresistance mediated by miR-140 in human osteosarcoma and colon cancer cells. Oncogene 2009; 28: 4065-4074.

52 Song B, Wang $Y$, Titmus MA, Botchkina G, Formentini A, Kornmann $M$ et al. Molecular mechanism of chemoresistance by miR-215 in osteosarcoma and colon cancer cells. Mol Cancer 2010; 9: 96.
53 Zhang H, Li W, Nan F, Ren F, Wang H, Xu Y et al. MicroRNA expression profile of colon cancer stem-like cells in HT29 adenocarcinoma cell line. Biochem Biophys Res Commun 2011; 404: 273-278.

54 Kong W, Yang H, He L, Zhao JJ, Coppola D, Dalton WS et al. MicroRNA-155 is regulated by the transforming growth factor beta/Smad pathway and contributes to epithelial cell plasticity by targeting RhoA. Mol Cell Biol 2008; 28: 6773-6784.

55 Park SM, Gaur AB, Lengyel E, Peter ME. The miR-200 family determines the epithelial phenotype of cancer cells by targeting the E-cadherin repressors ZEB1 and ZEB2. Genes Dev 2008; 22: 894-907.

56 Bitarte N, Bandres E, Boni V, Zarate R, Rodriguez J, Gonzalez-Huarriz M et al. MicroRNA-451 is involved in the self-renewal, tumorigenicity, and chemoresistance of colorectal cancer stem cells. Stem Cells 2011; 29: 1661-1671.

57 Yu Y, Kanwar SS, Patel BB, Oh PS, Nautiyal J, Sarkar FH et al. MicroRNA-21 induces stemness by downregulating transforming growth factor beta receptor 2 (TGFbetaR2) in colon cancer cells. Carcinogenesis 2012; 33: 68-76.

$58 \mathrm{Yu} \mathrm{XF,} \mathrm{Zou} \mathrm{J,} \mathrm{Bao} \mathrm{ZJ,} \mathrm{Dong} \mathrm{J.} \mathrm{miR-93} \mathrm{suppresses} \mathrm{proliferation} \mathrm{and} \mathrm{colony} \mathrm{for-}$ mation of human colon cancer stem cells. World J Gastroenterol 2011; 17: 4711-4717.

59 Zhu R, Yang Y, Tian Y, Bai J, Zhang X, Li X et al. Ascl2 knockdown results in tumor growth arrest by miRNA-302b-related inhibition of colon cancer progenitor cells. PLoS One 2012; 7: e32170.

60 Xu XT, Xu Q, Tong JL, Zhu MM, Nie F, Chen X et al. MicroRNA expression profiling identifies miR-328 regulates cancer stem cell-like SP cells in colorectal cancer. Br J Cancer 2012; 106: 1320-1330.

61 Di Fiore R, Fanale D, Drago-Ferrante R, Chiaradonna F, Giuliano M, De Blasio A et al. Genetic and molecular characterization of the human osteosarcoma 3AB-OS cancer stem cell line: a possible model for studying osteosarcoma origin and stemness. J Cell Physiol (in press).

Oncogenesis is an open-access journal published by Nature Publishing Group. This work is licensed under the Creative Commons AttributionNonCommercial-No Derivative Works 3.0 Unported License. To view a copy of this license visit http://creativecommons.org/licenses/by-nc-nd/3.0/ 